\title{
BOOK TRAILER "NAWUNG, PUTERI MALU DARI JAWA" DENGAN TEKNIK POP-UP PROJECTION MAPPING
}

\author{
Nissa Fijriani \\ Program Studi Animasi, Fakultas Seni Media Rekam, Institut Seni Indonesia Yogyakarta \\ nissafij@gmail.com
}

\begin{abstract}
Abstrak
Medium audiovisual merupakan medium yang efektif untuk menyampaikan informasi. Seni videografi melahirkan produk yang tidak hanya dapat menampilkan ekspresi penciptanya tetapi juga memiliki daya guna. Book trailer memiliki fungsi literasi yang dapat menjadi media komunikasi yang baik untuk melestarikan budaya membaca dengan merekomendasikan sebuah buku. Salah satu karakteristik audiovisual yang melibatkan lebih dari satu indera manusia untuk menikmatinya memiliki kekuatan tersendiri untuk mencapai sasarannya. Book trailer ini mengambil beberapa bagian cerita dalam novel "Nawung, Puteri Malu dari Jawa" yang dirangkai menjadi rangkaian cuplikan cerita. Alur yang disusun tersebut diwujudkan ke dalam format audiovisual dengan bentuk book trailer. Dengan menggunakan teknik pop-up projection mapping yang merupakan perpaduan antara teknik manual (paper cutting dan pop-up book) dan digital (motion graphic dan projection mapping), akan dibuat sebuah book trailer untuk merekomendasikan novel "Nawung, Puteri Malu dari Jawa" kepada masyarakat luas.
\end{abstract}

Kata kunci : book trailer, Pop-up projection mapping, projection mapping, literasi

\begin{abstract}
Audiovisual medium is an effective medium for conveying information. The arts of videography gives birth to products that can not only displays the expression of it's creator but also useful. Book trailers have a literacy function that can be a good communication medium for preserving a reading culture by recommending a book. One of audiovisual characteristics which involve more than one human senses to enjoy it has its own power to achieve its purpose. This book trailer takes some parts of the story in the novel "Nawung, Puteri Malu dari Jawa" which arranged into a series of story footage. The compiled plot will be translated into a book trailer format. By using the pop-up projection mapping technique which is a combination of manual techniques (paper cutting and pop-up books) and digital (motion graphics and projection mapping), a book trailer will be made to recommend the novel "Nawung, Puteri Malu dari Jawa"to the wider community.
\end{abstract}

Keywords : book trailer, Pop-up projection mapping, projection mapping, literation 


\section{PENDAHULUAN}

Era digital telah menggeser peran buku sebagai bahan bacaan. Buku digital atau e-book cukup digemari karena ekonomis dan praktis. E-book dapat disimpan di gadget dan dapat dibawa kemanapun tanpa menambah beban bawaan. Gerakan go green yang hinggga kini masih marak digaungkan memberikan penekanan kepada masyarakat untuk menghemat kertas guna menyelamatkan pohon. Seperti yang kita tahu, bahan utama buku adalah kertas yang tentu saja merampas nyawa jutaan pohon di muka bumi. Meskipun begitu, para penulis akan tetap menulis, penulis baru tetap akan bermunculan, perusahaan percetakan dan penerbitan tak akan berhenti memproduksi buku. Sebuah gambaran kondisi yang paradoks.

Berdasarkan riset ringan yang telah dilakukan, ada dua golongan calon pembaca buku, (1) calon pembaca yang membaca resensi, dan (2) calon pembaca yang tidak membaca resensi. Calon pembaca yang membaca resensi memang gemar mengulik dan mencari resensi-resensi buku dengan tujuan memantapkan niatnya untuk membeli buku tersebut untuk kemudian dibacanya, atau sekedar mencari judul buku yang recommended. Sebaliknya, calon pembaca yang tidak membaca resensi adalah orang-orang yang membeli buku berdasarkan rekomendasi lisan dari orang lain. Termasuk dalam golongan ini juga adalah orang yang membeli buku karena tertarik melihat desain sampulnya. Beberapa orang yang tidak membaca resensi buku karena tidak ingin membaca spoiler $^{l}$, atau memang hanya karena calon pembaca ini malas membaca.

Membaca adalah salah satu kegiatan yang sangat digemari oleh Nawung. Nawung adalah seorang anak yang hidup dengan keterbatasan finansial namun hal tersebut tidak menjadi penghalang untuk terus mencoba hal-hal yang baru dan menggali ilmu dan pengetahuan melalui buku yang ia kumpulkan sedikit demi sedikit dari hasil menabung. Melalui buku-buku bacaannya, Nawung tumbuh menjadi anak pintar dan cerdas serta memiliki banyak ide menarik untuk membuat kegiatan-kegiatan yang bermanfaat untuk kegiatan di lingkungannya.

1 Dalam media dan Internet, spoiler (Ing.) adalah tulisan atau keterangan mengenai suatu cerita, yang membeberkan jalan cerita tersebut. Membaca beberan dari suatu cerita dapat menyebabkan berkurangnya kesenangan membaca cerita itu, karena kesenangan membaca sebuah cerita biasanya tergantung kepada dramatisasi atau ketegangan yang ditimbulkan oleh cerita tersebut. 
Nawung adalah nama tokoh dalam sebuah novel fiksi dengan judul "Nawung, Puteri Malu dari Jawa" yang mengedepankan kearifan lokal lewat budaya Jawa dan disajikan dengan alur cerita yang sangat menyenangkan. Kisah perjalanan hidup Nawung yang mencerminkan sifat yang dimiliki oleh setiap anak muda yang memiliki gairah untuk menggeluti indahnya berbagai nilai kehidupan termasuk pengetahuan, seni, cinta, dan hubungan interpersonal yang kaya kasih, namun sikap hidup kompromis orang Jawa yang selalu berusaha merangkul kesatuan harmonis antara dunia batin dan realitas yang dihadapinya dengan antara lain menghindari konflik, dituturkan secara apa adanya dan sangat mengalir oleh Galuh Larasati, penulisnya.

Novel yang dapat dibaca oleh semua usia ini layak direkomendasikan kepada masyarakat luas untuk mengenal budaya dan filosofi kehidupan masyarakat Jawa yang diterapkan dalam kehidupan sehari-hari. Nilai-nilai tersebut sudah selayaknya kembali dipahami agar mampu mengiringi kembali bersyukurnya jiwa nilai-nilai filosofi kehidupan masyarakat Jawa yang diterapkan dalam kehidupan sehari-hari.

Sebuah produk yang memuat ulasan tentang sebuah buku dibutuhkan oleh calon pembaca sebagai panduan untuk mengetahui garis besar isi sebuah buku. Calon pembaca yang ingin mengetahui lebih lanjut mengenai isi buku tersebut selanjutnya akan mencarinya ke perpustakaan, toko buku, atau situs-situs penjualan buku di dunia maya. Bentuk dari ulasan buku umumnya berupa tulisan dan dimuat di media cetak seperti koran dan majalah serta di media online.

Medium yang digunakan untuk menghadirkan ulasan buku kepada calon pembaca buku kini berkembang dengan memanfaatkan media audiovisual. Produk ini dikenal dengan nama book trailer. Book trailer pada mulanya adalah sebuah komersil yang bertujuan untuk mempromosikan sebuah buku. Seiring perkembangannya, book trailer dapat dimanfaatkan sebagai media literasi buku dengan mengenalkan buku kepada masyakarat.

Seni videografi merupakan bagian dari seni media rekam yang mengandung unsur audiovisual merupakan medium yang efektif untuk menyampaikan informasi. Seni videografi melahirkan produk yang tidak hanya dapat menampilkan ekspresi pembuatnya tetapi juga memiliki daya guna. Dengan demikian, produk book trailer dapat dimasukkan 
dalam kategori karya seni terap (seni terapan) atau applied art. Soedarso Sp. menerangkan bahwa "Seni terap atau applied art adalah seni yang diterapkan atau diaplikasikan pada soal-soal lain di luar ekspresi estetik" (Soedarso, 2006:101). Dalam hal ini, book trailer yang memiliki fungsi literasi dapat menjadi media komunikasi yang baik mengingat karakteristik audiovisual yang melibatkan lebih dari satu indera manusia untuk menikmatinya memiliki kekuatan tersendiri untuk mencapai sasarannya.

Mengenalkan buku kepada masyarakat melalui ulasan buku adalah sebuah proses komunikasi yang bertujuan melestarikan budaya membaca kepada masyarakat. Melalui proses ini, minat membaca masyarakat khususnya untuk generasi muda dapat kembali meningkat.

Sampai saat ini, cara merekomendasikan buku dapat dikategorikan dalam tiga cara yaitu (1) lisan, atau yang disampaikan secara langsung secara verbal dari mulut ke mulut, (2) tulisan, yang ditulis dan dipublikasikan melalui media cetak atau elektronik, dan (3) media audiovisual dalam bentuk book trailer.

Review buku merupakan salah satu metode merekomendasikan buku secara tulisan. Review buku, yang juga disebut dengan resensi, biasa kita jumpai pada sebuah media cetak maupun media elektronik yang bertujuan untuk merekomendasikan sebuah buku kepada calon pembaca. Dalam resensi buku dipaparkan garis besar isi cerita, tanggapan si pembuat resensi atas sebuah buku yang diulasnya, setra blurb (testimoni yang (biasanya) terdapat pada sampul buku bagian belakang).

"Sejalan dengan perkembangan kecerdasan berpikir manusia, diciptakanlah sebuah alat bantu untuk mendukung proses komunikasi. Bermula dari mengembangkan dan membangun teori-teori dasar yang bersifat mekanis dan teori dasar elektronika seperti gelombang elektromagnetik atau sinyal listrik yang ditemukan pada awal abad 19, kemudian berkembang ke dalam teknologi komunikasi yang memiliki kemampuan mempercepat penyebaran informasi di berbagai tempat dan lapisan masyarakat. Hasilnya melahirkan sebuah peradaban baru, yaitu kehidupan yang tidak lagi dibatasi ruang dan waktu". (Luthfi , 2010:12) 
Ulasan tentang buku berkembang seiring dengan berkembangnya teknologi. Book trailer lahir sebagai media untuk mengenalkan buku kepada masyarakat dengan memanfaatkan teknologi audiovisual dan internet untuk penyebarannya.

Book trailer merupakan bentuk perkembangan dari film trailer. Sejarah lahirnya book trailer tak lepas dari sejarah film trailer yang lebih dulu lahir dan menjadi populer sebagai media untuk mengenalkan film kepada masyarakat.

Film trailer adalah video yang terdiri dari cuplikan-cuplikan sebuah film yang akan tayang di bioskop. Tujuan diproduksinya film trailer adalah mempromosikan film tersebut.

Film trailer pertama kali dipertontonkan di Amerika Serikat pada November 1913, ketika Nils Granlund memproduksi sebuah promosi pendek untuk film musikal The Pleasure Seekers yang dibuka di Winter Garden Theatre, Broadway. Granlund juga memperkenalkan film trailer untuk pertama kalinya untuk sebuah pertunjukan gambar yang digerakkan dengan menggunakan teknik slide yang dibintangi oleh Charlie Chaplin (Granlund 1957:53).

Bentuk film trailer yang di awal kemunculannya menampilkan teks mulai berubah seiring berkembangnya teknologi. Film trailer ini diakui sebagai produk yang memiliki sense of art sebab proses pembuatannya membutuhkan keahlian editing khusus. Film trailer memuat shot-shot pilihan yang diambil dari film yang akan dipromosikan. Mengingat tujuan utama film trailer adalah menarik perhatian siapapun yang menyaksikannya, bagian dari film yang biasanya dipilih adalah yang paling menarik, lucu, atau mengandung poin penting dalam film tersebut dengan catatan tidak mengandung spoiler (tidak membocorkan isi cerita secara eksplisit). Durasi maksimal film trailer, seperti yang ditentukan oleh Motion Picture Association of America (MPAA) adalah tidak lebih dari 2 menit 30 detik.

Atas dasar-dasar film trailer tersebutlah book trailer lahir. Awal terlahirnya book trailer hanya berupa cuplikan still images dari ilustrasi atau isi sebuah buku. Seiring berkembangnya teknik audiovisual, bentuk book trailer semakin beragam. 


\section{Alih Wahana}

"Ada banyak hal yang mendorong terciptanya sebuah karya seni, salah satunya adalah keinginan manusia yang hakiki yaitu untuk berkomunikasi dengan sesamanya" (Soedarso, Sp., 2006 : 119). Leo Tolstoy dalam Soedarso Sp. (2006 : 124,126) menyatakan bahwa seni adalah sarana komunikasi bagi emosi dan kita tahu bahwa komunikasi memerlukan adanya komunikator, si seniman, dan komunikan, yaitu masyarakat ramai. Maka seni adalah penghubung antara seniman dengan masyarakatnya. Ide yang mendorong perancangan karya book trailer ini adalah keinginan yang besar untuk mengajak masyarakat untuk membaca. Untuk mencapai hal tersebut, diperlukan sebuah medium yang memuat informasi mengenai sebuah buku. Book trailer merupakan sebuah medium alternatif untuk mencapai hal tersebut.

Suatu karya sastra atau seni memiliki media atau wahana yang digunakan untuk dapat diapresiasikan. Sebuah novel menggunakan wahana teks, film menggunakan gambar 'bergerak', komik menggunakan gambar 'diam', dan tari menggunakan gerak tubuh. Penggunaan wahana suatu karya juga dapat berpindah dengan judul yang sama atau pengadopsian suatu karya dari suatu wahana ke wahana lainnya. Perpindahan wahana tersebut diistilahkan sebagai alih wahana.

"Alih wahana adalah perubahan dari satu kesenian ke jenis kesenian lain" (Damono 2009 : 121). perubahan wahana tersebut tidak terbatas pada satu atau dua jenis karya. Damono juga menambahkan bahwa karya sastra tidak hanya diterjemahkan dari satu bahasa ke bahasa lainnya, tetapi juga dialihwahanakan atau diubah menjadi kesenian lainnya. Berdasarkan pernyataan tersebut dapat dikatakan bahwa suatu karya dapat dialihwahanakan menjadi bentuk lain. Misalnya karya sastra dialihwahanakan menjadi bentuk pertunjukan teater atau film.

Berdasarkan uraian di atas, penciptaan book trailer yang merupakan salah satu produk audiovisual juga merupakan salah satu bentuk alih wahana yang mengubah wahana 'teks' dalam sastra menjadi gambar 'bergerak' untuk karya videografi. 


\section{Book Trailer}

"Book trailer adalah sebuah video promosi sebuah buku yang menggunakan teknik yang hampir sama dengan film trailer untuk mengenalkan buku tersebut sekaligus meningkatkan jumlah pembaca" (Chmielewski, 2006). Banyak website, blog, dan penjual online yang meraih sukses sukses dengan menggunakan video sebagai daya tarik untuk menarik minat masyarakat, hal ini menjadi alasan mengapa book trailer akan efektif digunakan sebagai media untuk promosi buku (Deval, 2008:242).

Beberapa penerbit buku kini menjadikan book trailer sebagai langkah promosi yang penting. Visualisasi yang biasa ditampilkan dalam book trailer berupa aktor yang berakting sesuai dengan cerita di dalam buku dan menyerupai film trailer, animasi, maupun still photo yang dipadukan dengan musik dan teks yang menggambarkan bagian dari isi buku (Fox, 2006). Bentuk lain dari book trailer adalah author readings atau interview yang terdiri atas footage video sang penulis menarasikan bagian dari buku yang ditulisnya, atau video interview dengan penulis (Kneschke, 2012).

Dua jenis book trailer yang disebutkan oleh Jacqueline Deval (2008:252) adalah book trailer yang diproduksi oleh publisher atau penerbit untuk kepentingan komersil, dan book trailer yang dibuat sendiri oleh penulis buku tersebut.

Potensi book trailer dalam memperkenalkan dan merekomendasikan buku kepada masyarakat sangat besar mengingat siapapun dapat mengakses data yang diunggah ke internet dengan sangat mudah. Ini adalah kesempatan yang dapat dimanfaatkan oleh para pecinta buku khususnya yang dekat dengan bidang audiovisual untuk membuat book trailer untuk sebuah buku dan mengunggahnya dengan maksud merekomendasikan sebuah buku kepada masyarakat tanpa mengandung unsur komersialitas.

Melihat perkembangan media promosi buku seperti yang diuraikan sebelumya, seni video sebagai salah satu cabang seni yang melibatkan perkembangan teknologi, dapat ambil bagian dan berperan serta memperkenalkan buku sekaligus melestarikan budaya membaca buku melalui media audiovisual dengan memproduksi book trailer yang dibuat tanpa tendensi yang berhubungan dengan komersialitas karena diciptakan oleh insan seni, bukan oleh sebuah perusahaan penerbitan. 
Mengacu pada Chuck Samburino (2013) dalam artikelnya "How to Make Book Trailer : 6 Tips” pada situs Reader's Digest, book trailer yang diajukan ini adalah sebuah karya audiovisual yang unsur naratifnya diambil dari rangkuman buku yang akan diangkat. Rangkuman tersebut kemudian dituliskan sebagai naskah untuk narasi, tidak semerta-merta mengutip bagian dai isi buku. Unsur visualnya akan dibangun dari ilustrasi yang terdapat di dalam buku. Di akhir durasi akan dimunculkan cover buku serta dicantumkan informasi mengenai judul buku, pengarang, dan tahun terbitan.

Penyebarluasan produk-produk book trailer ini nantinya bisa diakses oleh siapapun dan bermanfaat sebagai upaya pengenalan buku dan secara tidak langsung mengajak untuk membaca buku tersebut.

\section{Pop-up}

"The earliest known book to use a movable part was produced in the 13th century by Catalan mystic and poet Ramon Llull of Majorca who used a revolving disc or volvelle to illustrate his theories. Books with movable parts produced during this era, were made for the purpose of educating and conveying ideas to literate adults in a more precise way than could be achieved with a static illustration."(Puleo, 2011:10)

Kutipan di atas menyebutkan bahwa cikal bakal pop-up book diciptakan pada abad ke-13 dan digunakan sebagai alat peraga untuk menjelaskan sebuah teori dengan wujud ilustrasi. Puelo juga menuliskan bahwa dalam perkembangannya, teknik pop-up banyak digunakan dalam buku ilustrasi untuk anak-anak.

Teknik рор-ир kemudian menginspirasi bidang audiovisual seperti film dan animasi. Pada tahun 2007, Kevin Lima, sutradara film rilisan Disney dengan judul "Enchanted" menampilkan beberapa scene yang dibuat dengan materi pop-up book. Sebuah film animasi pendek berjudul "The Happy Ducklings” (2008) menampilkan unsur visual dengan mengadaptasi teknik pop-up book dan mewujudkannya dengan teknik animasi. (Puelo, 2011:30).

"Paper pop-ups or movable books are three dimensional books that contain paper pieces that pop out or move when the book is opened and fold completely flat when the book is closed" (R.Ruiz Jr., dkk., 2014:1) 
Visualisasi pop-up book yang membuat gambar dua dimensi seolah-olah menjelma menjadi gambar tiga dimensi ketika buku tersebut dibuka, membuat pop-up book banyak digemari dan menginspirasi banyak orang untuk berkesperimen dengan teknik dan material dan menggabungkannya dengan disiplin ilmu yang dapat mendukung terwujudnya karya visual yang baru dan menarik.

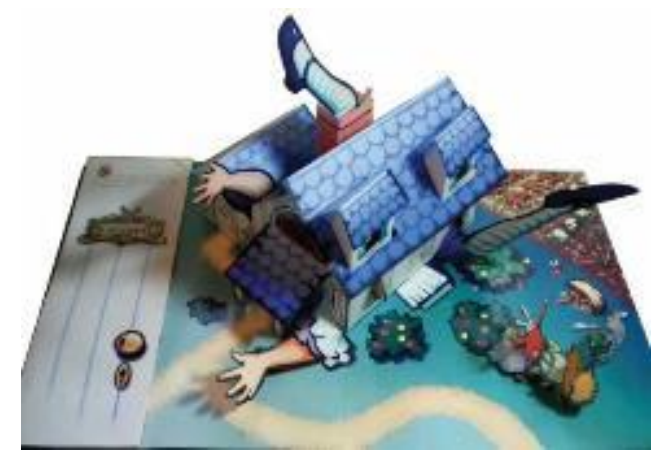

Gambar 1. Contoh pop-up pada sebuah buku cerita untuk anak-anak

"Alice's Advamture in Wonderland" karya Robert Sabuda (2013)

Sumber: "Next Stop: Pop-Ups. The Influence of Paper Engineering on Visual Media" (Puelo,2003:19)

Conrado R. Ruiz Jr.,dkk. Menuliskan sebuah terminologi dasar untuk pop-up dalam sebuah artikel berjudul Multi-style Paper Pop-up Designs from 3D Models. Sebuah pop-up dibuat dengan melipat dan menempel beberapa bagian kertas. Terdiri atas satu set bagianbagian potongan kertas dari bentuk yang telah direncanakan (patch) yang terhubung pada satu garis lurus (hinge) berupa garis lipatan. Pop-up berada diantara dua patches utama yang disebut ground dan backdrop, yang terhubung oleh sebuah lipatan tepat di tengah (central fold).

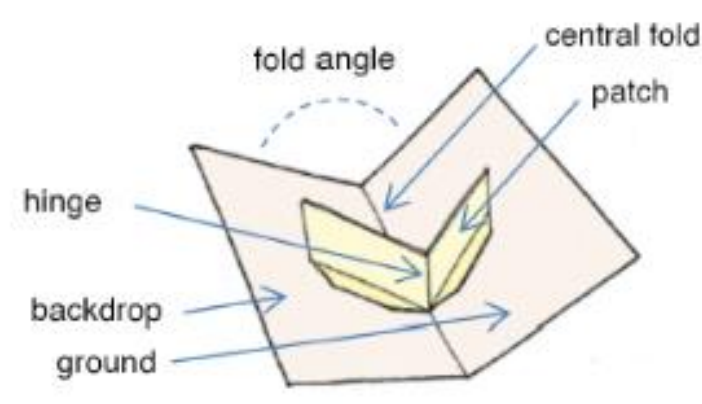

Gambar 2. Pop-up basic terminology

Sumber: Ruiz Jr.,dkk. (2013) 
Pemahaman dasar tentang pop-up tersebut digunakan sebagai acuan pembuatan set pop-up yang akan dirancang untuk penciptaan karya seni ini.

\section{Projection Mapping}

Brett Jones, seorang praktisi projection mapping yang bekerja di Walt Disney menyatakan dalam artikelnya yang berjudul "The Illustrated History of Projection Mapping” dalam situs www.projectionmapping.org, teknik projection- mapping pertama kali digunakan oleh Disney pada tahun 1960an dalam acara pembukaan sebuah wahana permainan "Haunted Mansion" di Disneyland. Catatan sejarah berikutnya adalah tahun 1980, seorang seniman benama Michael Naimark membuat sebuah karya instalasi yang merekam orang berinteraksi dengan benda-benda di sebuah ruangan kemudian memproyeksikan video rekaman tersebut ke sebuah ruangan. Karya ini menciptakan ilusi optikal seolah-olah orang yang berinteraksi dengan benda tersebut benar-benar berada di ruangan itu.

Video projection mapping kemudian berkembang dan kini banyak digunakan oleh para video artist. Beberapa diantaranya menggunakan gedung maupun bangunan bersejarah sebagai media proyeksi. Selain itu, karya-karya video mapping juga banyak dipamerkan di galeri seni dengan menampilkan objek-objek menarik dan inovatif sebagai media proyeksinya.

Perkembangan teknologi memungkinkan semua disiplin ilmu kesenian berkolaborasi dan menciptakan karya-karya baru yang segar dan inovatif. Perancangan karya seni audiovisual yang akan dirancang sebagai applied art-pun dapat bereksperimen dengan teknik dan material yang beragam.

\section{Novel "Nawung, Puteri Malu dari Jawa"}

Novel "Nawung, Puteri Malu dari Jawa" bercerita tentang kisah hidup Nawung yang tumbuh besar di lingkungan desa di kaki bukit Menoreh dan dekat dengan Borobudur. Pola hidup sederhana serta beberapa ajaran mengenai filosofi kehidupan Jawa yang 
diajarkan oleh orangtuanya membuat Nawung tumbuh menjadi gadis yang cerdas dan mandiri. Dengan membaca novel ini, pembaca akan mendapatkan pengetahuan tentang nilai-nilai kehidupan, nasehat, serta inspirasi akan hidup sederhana.

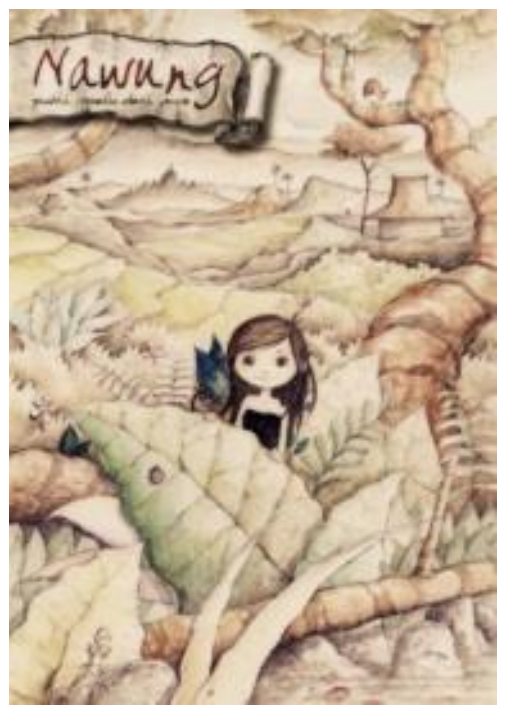

Gambar 3. Cover novel "Nawung, Puteri Malu dari Jawa" Sumber : Galuh Larasati

Nasehat untuk kehidupan seperti "ajining diri saka lathi” (harga diri seseorang bergantung dari apa yang dikatakannya) yang merupakan nasehat supaya berhati-hati dalam berkata-kata, "aja adigang, adigung, adiguna" (jangan menyombongkan kekuatan, kekayaan, dan ilmu) akan ditemui pembaca pada babak awal kehidupan Nawung.

Babak kehidupan Nawung dibagi menjadi sebelas bagian yang diberi judul tembang Macapat Jawa. Dalam sebuah wawancara dengan Galuh Larasati, penulis novel ini, mengutarakan bahwa Macapat Jawa, jika diurutkan ternyata menggambarkan lingkaran hidup manusia. Bahwasanya setiap manusia akan melewati tahapan-tahapan kehidupan seperti yang dituliskan dalam Tembang Macapat.. Hal tersebut menambah daftar pengetahuan tentang budaya Jawa yang bisa didapatkan oleh pembaca.

Novel ini diperkuat dengan ilustrasi menarik yang dapat mengantarkan imajinasi pembacanya mengenai karakter dan lingkungan tempat Nawung tinggal. 

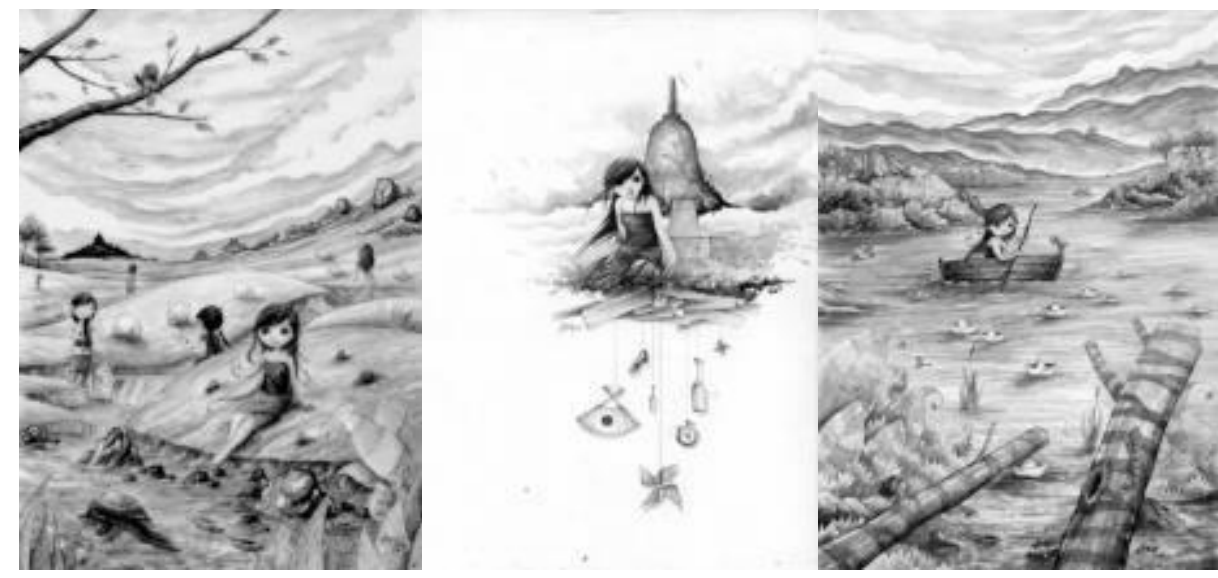

Gambar 4. Beberapa Ilustrasi dalam Novel

"Nawung, Puteri Malu dari Jawa"

Sumber : Galuh Larasati

\section{METODE PENCIPTAAN}

\section{BOOK TRAILER "NAWUNG, PUTRI MALU DARI JAWA"}

Metode penciptaan book trailer untuk novel "Nawung, Puteri Malu dari Jawa" melalui proses seleksi, eksplorasi, eskperimen/improvisasi, serta pembentukan/perwujudan dengan uraian sebagai berikut :

\section{Seleksi}

Proses penyeleksian dilakukan dengan tujuan memilih buku apa yang akan diangkat menjadi materi untuk diciptakan previsualisasinya dalam wujud book trailer. Faktor-faktor yang bisa dipertimbangkan adalah nilai yang terkandung dalam cerita pada buku tersebut. Buku yang menyandang predikat best seller di pasaran belum tentu memiliki nilai moral yang baik, maka proses pemilihan buku ini bisa berdasarkan pengamalam empiris dan estetis pembuat, ataupun berawal dari rekomendasi seseorang yang terpercaya. Pada proses penciptaan yang dirancang untuk tugas akhir penciptaan seni ini, dipilih sebuah buku berjudul "Nawung, Puteri Malu dari Jawa".

Proses seleksi juga dilakukan pada pemilihan ilustrasi yang akan digunakan untuk dimunculkan dalam book trailer ini. dari 32 ilustrasi yang 
terdapat dalam novel ini, dipilih beberapa yang dapat mewakili visualisasi dari narasi.

\section{Eksplorasi}

Eksplorasi adalah tahapan penetapan ide dan tema. Primadi (2000: 1) menyebutkan bahwa proses berpikir dan proses kreasi adalah adalah nama yang berbeda bagi proses yang sama, yaitu proses imajinasi. Maka dalam proses imajinasi dibutuhkan media yaitu image.

Buku "Nawung, Puteri Malu dari Jawa" dilengkapi dengan ilustrasi pendukung yang membentuk image tokoh Nawung yang diciptakan oleh Day. Tantangan yang harus dihadapi adalah "menghidupkan" ilustrasi tersebut menjadi sebuah book trailer. Setelah mempertimbangan beberapa wujud visual dan teknis, maka diputuskan ilustrasi tersebut akan digerakkan dengan menggunakan perangkat lunak yang mendukung. Untuk mewujudkannya akan dilakukan sedikit improvisasi atas ilustrasi yang sudah ada sebelumnya. Proses tersebut akan dikerjakan tanpa mengubah esensi dari ilustrasi dan isi buku "Nawung, Puteri Malu dari Jawa".

Gambar-gambar ilustrasi tersebut diolah dengan perangkat lunak atau software Adobe Photoshop untuk menyeleksi elemen-elemen yang dibutuhkan untuk materi video. Proses menggerakkan ilustrasi menggunakan perangkat lunak atau software Adobe Premiere. Materi tersebut nantinya akan digunakan sebagai materi proyeksi video ke media pop up book.

Eksplorasi selanjutnya adalah merangkum isi buku dan memilahnya untuk dijadikan naskah audiovisual serta merancang setting yang akan diwujudkan menjadi pop-up book sebagai media proyeksi untuk karya video ini. Tahapan pembuatan set pop-up tak akan lepas dari teknik paper cutting, maka eksplorasi untuk menguasai teknik paper cutting lebih dulu dilakukan 


\section{Eksperimen}

Eksperimen yang dilakukan sama dengan tahapan rehearsal seperti yang umumnya dilakukan pada tahapan produksi audiovisual. Mempelajari dengan seksama teknik yang akan digunakan untuk menghadirkan Nawung ke calon pembaca dengan format audiovisual yaitu teknik pop-up projection mapping. Pemilihan material yang akan digunakan sebagai bahan pop-up book serta konstruksi penyusun juga merupakan eksperimen yang akan dilakukan pada tahapan ini.

\section{Perwujudan}

Sebagai salah satu produk audiovisual, proses perwujudan karya book trailer dengan durasi 3 menit ini akan tetap menerapkan tahapan metode penciptaan seperti yang biasa digunakan dalam produksi produk audiovisual. Cleve (2006: 9) menyebutkan ada 4 (empat) tahap dalam produksi film yaitu development, pre-production, production dan post-production.

a. Development dalam proses penciptaan ini adalah tahap pengembangan ide dan penyusunan naskah naratif, merancang desain yang akan digunakan, serta eksplorasi material dan teknik untuk proses paper cutting dan projection mapping seperti yang telah dijabarkan sebelumnya.

b. Pre-production mencakup persiapan-persiapan sebelum produksi dilakukan. Termasuk di dalamnya adalah mengumpulkan, menyeleksi dan mengolah materi ilustrasi dalam novel "Nawung, Puteri Malu dari Jawa" yang akan digunakan sebagai panduan produksi, menyiapkan keperluan produksi lainnya seperti menghimpun kerabat kerja produksi, menyiapkan alat, serta pop up book yang akan digunakan sebagai media proyeksi.

c. Production mencakup persiapan-persiapan sebelum produksi dilakukan termasuk di dalamnya adalah penyusunan naskah naratif, merancang desain yang akan digunakan, eksplorasi material dan 
teknik untuk proses paper cutting dan projection mapping., hingga rehearsal, proses recording VO (voice over) yang akan digunakan sebagai narasi, serta menyusun musik yang akan digunakan sebagai backsound.

Post-production adalah tahap editing akhir, merangkai seluruh materi menjadi bentuk akhir yang siap ditonton dan mempersiapkan pameran. 


\section{Bagan Urutan Proses Penciptaan}

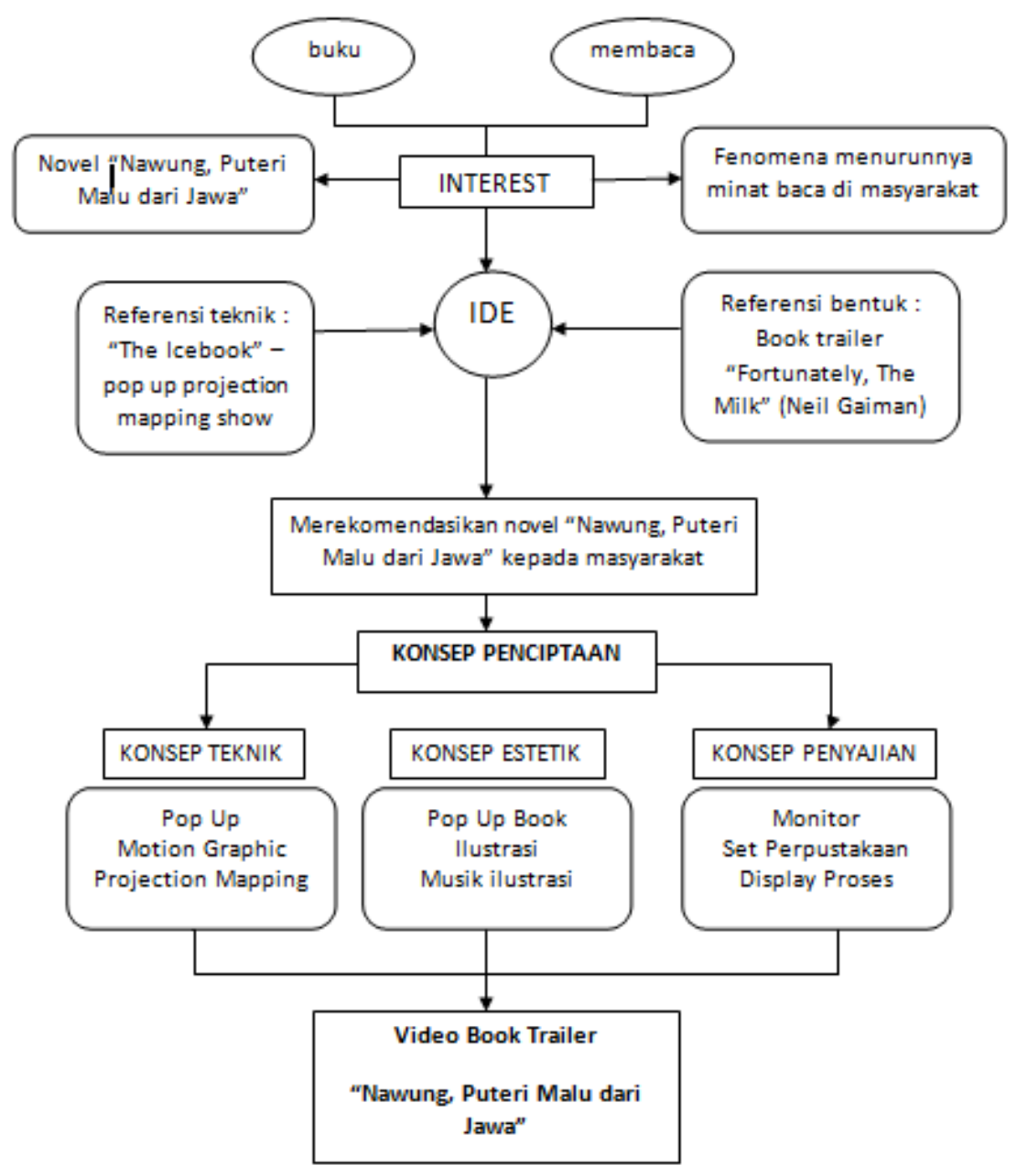

Gambar 5. Bagan urutan proses penciptaan

\section{ULASAN KARYA}

\section{Konten Video}

a. Ilustrasi

Salah satu elemen pendukung visual dalam book trailer "Nawung, Puteri Malu dari Jawa” adalah ilustrasi yang terdapat dalam buku novel tersebut. Ilustrasi merupakan salah satu kekuatan yang dimiliki oleh novel 
ini. Karakter Nawung diciptakan oleh sang ilustrator dengan menggunakan teknik drawing dengan menggunakan pensil dan dipadukan dengan watercolor. Dari 32 ilustrasi yang terdapat dalam novel ini, terpilih 17 ilustrasi yang mendukung visualisasi dari narasi yang ada.

Image yang digunakan didapatkan dari hasil scan master ilustrasi atau gambar asli. Warna hitam dan putih pada ilustrasi tetap dipertahankan hingga pada tahap editing video untuk tetap memberikan kesan seperti melihat ilustrasi pada buku. Dari proses scan tersebut diperoleh gambar dengan resolusi tinggi yang memenuhi kebutuhan editing. Untuk menghadirkan karakter Nawung melalui media audiovisual, ilustrasi yang sudah menjadi file digital tersebut diolah menggunakan software Adobe Premiere CS6. Software ini memungkinkan penyusunan gambar bersamaan dengan penyesuaian durasi file audio narasi. Pengolahan gambar salah satu ilustrasi asli menjadi file yang dibutuhkan dalam proses editing dapat dilihat pada gambar berikut :

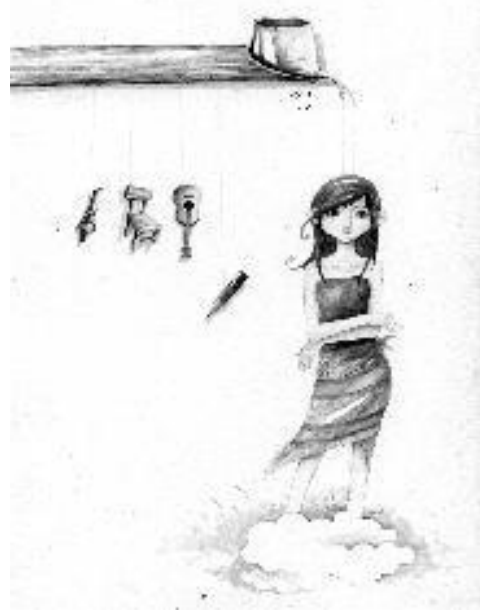

Gambar 6. Salah satu ilustrasi dalam novel "Nawung, Puteri Malu dari Jawa" Sumber : Arsip pribadi Galuh Larasati 


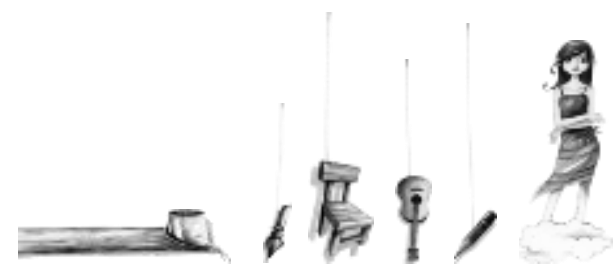

Gambar 7. Ilustrasi yang sudah dipisah menjadi beberapa file untuk kepentingan penggarapan video.

Sumber : dokumentasi pribadi

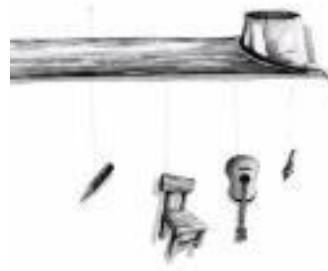

Gambar 8. Ilustrasi yang sudah diatur tata letaknya sesuai dengan komposisi video Sumber : book trailer "Nawung, Putri Malu dari Jawa"

Ketiga gambar di atas memberi gambaran tentang proses pengolahan file ilustrasi menjadi video. Pergerakan yang ada dalam video didapatkan dari hasil menentukan keyframe pada tiap-tiap image.

\section{b. Pop Up}

Perancangan desain pop-up book menyesuaikan ilustrasi asli yang ada.

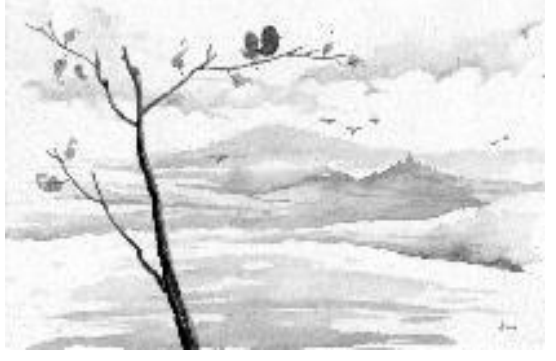


Gambar 9. Ilustrasi asli dalam novel yang menjadi gambar pembuka dalam book trailer "Nawung, Puteri Malu dari Jawa"

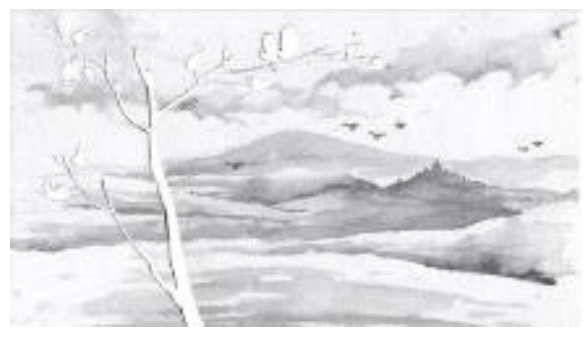

Gambar 10. Ilustrasi yang sudah diolah untuk mendapatkan desain pop-up

Bentuk yang didapat untuk desain pop-up kemudian dicetak pada kertas jenis Ivory $190 \mathrm{gsm}$. Untuk menujudkan bentuk yang diinginkan, hasil cetak tersebuh dikerjakan dengan teknik paper cutting.
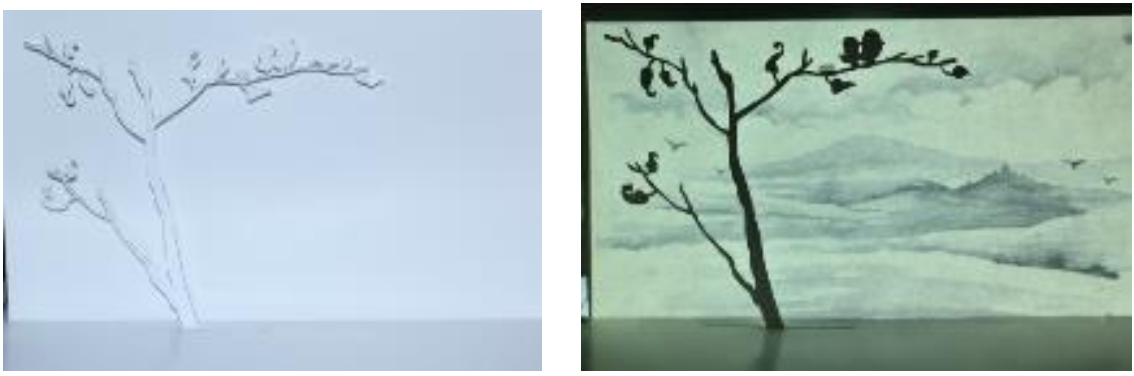

Gambar 11. Desain pop-up sebelum dan sesudah proyeksi 1 Sumber : book trailer "Nawung, Putri Malu dari Jawa"
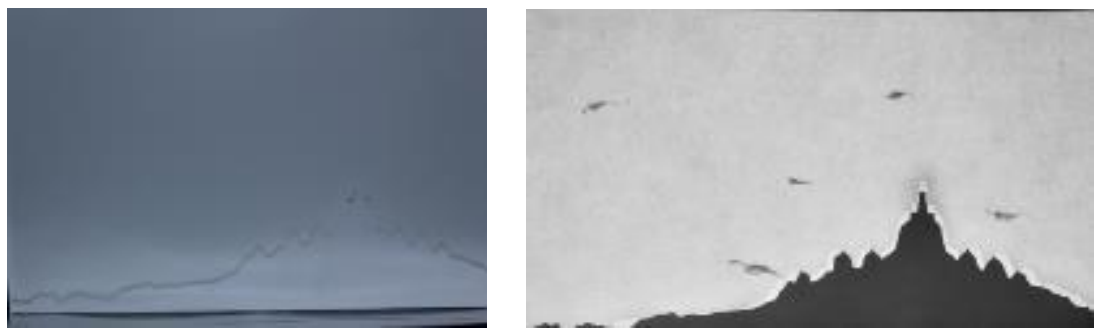

Gambar 12. Desain pop-up sebelum dan sesudah proyeksi 2 Sumber : book trailer "Nawung, Putri Malu dari Jawa" 

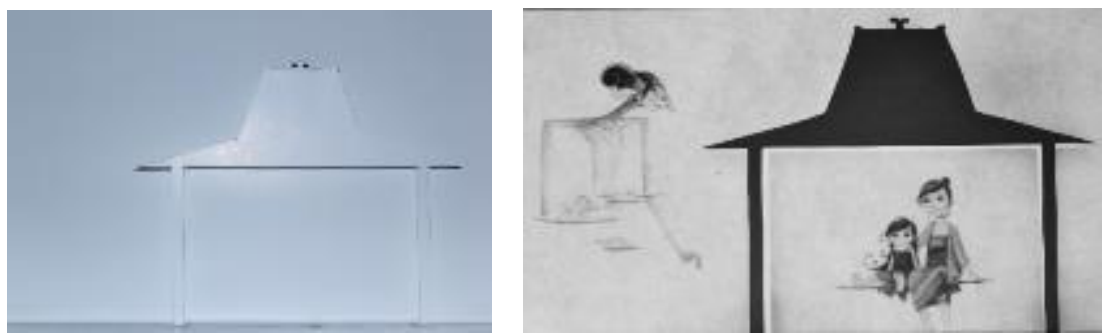

Gambar 13. Desain pop-up sebelum dan sesudah proyeksi 3 Sumber : book trailer "Nawung, Putri Malu dari Jawa"
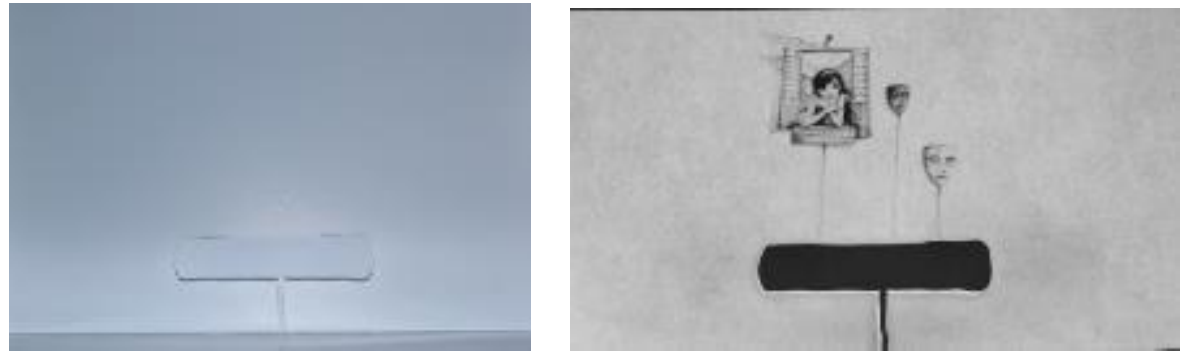

Gambar 14. Desain pop-up sebelum dan sesudah proyeksi 4 Sumber : book trailer "Nawung, Putri Malu dari Jawa"
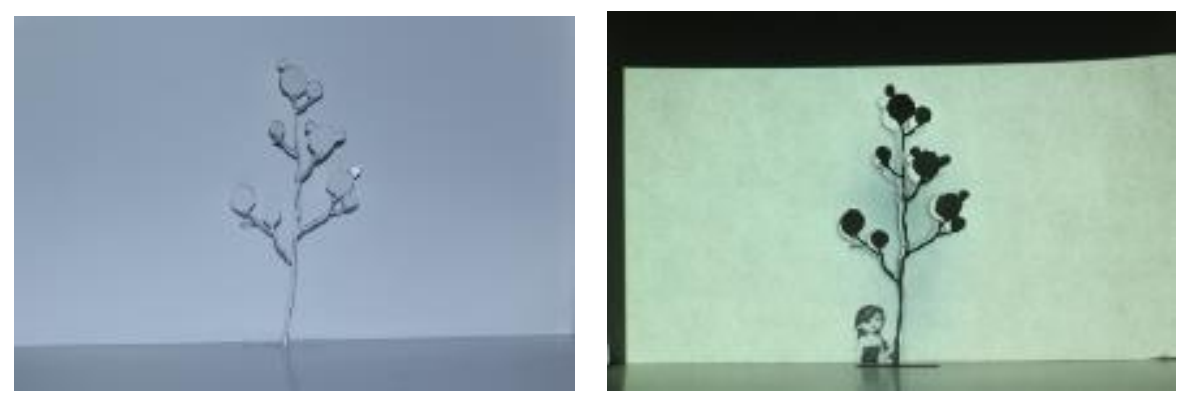

Gambar 15. Desain pop-up sebelum dan sesudah proyeksi 5 Sumber : book trailer "Nawung, Putri Malu dari Jawa"

Pengambilan gambar dilakukan setelah proses pembuatan motion graphic untuk ilustrasi dan pembuatan pop-up book selesai. Materi hasil editing motion graphic diproyeksikan pada media pop-up book. Pengambilan gambar dilakukan untuk mendapatkan footage yang akan disusun kembali menjadi book trailer. 
Proses proyeksi video pada bidang pop-up mendapatkan hasil yang unik. Serat pada kertas menghasilkan tekstur yang tidak terduga dan memberikan kesan tersendiri pada gambar yang dihasilkan. Hasil akhir dari video ini akhirnya mendapatkan tekstur yang memberikan kesan seolah audiens melihat ilustrasi bergerak dalam sebuah buku. Pengalaman estetis ini diharapkan dapat menarik minat audiens untuk membaca buku "Nawung, Putri Malu dari Jawa”.

\section{Konten Audio}

a. Narasi

Narasi dibacakan oleh Galuh Larasati, penulis novel "Nawung, Puteri Malu dari Jawa". Dipilihnya Galuh Larasati sebagai VO (Voice Over) talent book trailer untuk novel yang ditulisnya sendiri memiliki alasan yang kuat. Seorang penulis novel pastilah sangat mengenal apa yang ditulisnya. Keterikatan antara penulis dan karyanya memberi kekuatan tersendiri, kekuatan tersebut yang membuat hasil perekaman suara seolah menjadi narasi yang "bernyawa". Galuh juga menyumbangkan suaranya untuk bernyanyi dalam satu bait yang ceria untuk memperkuat karakter novel ini.

b. Ilustrasi musik

Hasil akhir aransemen musik untuk book trailer "Nawung, Puteri Malu dari Jawa" merupakan hasil diskusi antara sutradara dan music designer. Hasil dari diskusi tersebut memutuskan bahwa aransemen musik untuk video ini sebaiknya mengalun mengiringi pembacaan narasi yang seperti membacakan dongeng kepada penontonnya dan tetap memasukkan unsur intrumen musik Jawa di dalamnya. 


\section{PENUTUP}

Menciptakan produk seni yang memiliki nilai guna (applied art) memiliki tantangan tersendiri. Selain harus mempertimbangkan ketepatan cara penyajian, karya tersebut juga harus tepat sasaran. Proses penciptaan karya book trailer "Nawung, Puteri Malu dari Jawa" telah dirancang dan melalui tahapan-tahapan produksi yang sesuai dengan kaidah metode penciptaan. Penggunaan teknik pop-up projection mapping mendatangkan banyak pelajaran baru untuk penulis.

Book trailer yang diciptakan ini memiliki tujuan utama merekomendasikan novel "Nawung, Putri Malu dari Jawa", perancangan konsep visual dibuat semenarik mungkin hingga pada akhirnya penonton akan tertarik membaca novel ini. Membuat book trailer adalah tantangan baru bagi masyarakat seni audiovisual. Dengan membuat book trailer, para seniman audiovisual dapat turut serta melestarikan budaya membaca.

Pemahaman mendalam tentang sebuah buku yang akan diangkat menjadi book trailer sangatlah penting untuk mendapatkan esensi dari buku tersebut. Banyak hal yang harus dipersiapkan demi mencapai hasil yang diinginkan. Harapan penulis, book trailer ini dapat menjadi salah satu referensi yang layak untuk penciptaan karya serupa berikutnya.

\section{DAFTAR PUSTAKA}

\section{Buku :}

Bosko, Mark Steven, 1965, The Complete Independent Movie Marketing Handbook, Michael Wiese Productions, CA.

Cleve, Bastian, 2006, Film Production Management, Third Edition, Focal Press, Burlington, MA.

Damono, Sapardi Djoko, 2001, Sastra Bandingan, Jakarta : Editum.

Deval, Jacqueline, 2008, Publicize Your Book (Updated) : An Insider's Guide to Getting Your Book The Attention It Deserves, Perigge Trade, NY

Granlund, N.T, 1957, Blondes, Brunettes, and Bullet",.; Van Rees Press, NY. Kridalaksana, 2008, Kamus Linguistik, Jakarta, PT, Gramedia.

Larasati, Galuh, 2013, Nawung, Puteri Malu dari Jawa, Galangpress : Yogyakarta. Muis, A., 1991, Kecenderungan Globalisasi Media Massa, Jurnal Analisis, CSIS. 
Puelo, Bernadette, 2011, Next Stop: Pop-Ups. The Influence of Paper Engineering on Visual Media, Pennsylvania : Marywood University.

R, Alexandri Luthfi, 2010, Program Acara Televisi: Kualitas dan Pengaruhnya terhadap Khalayak Pemirsa, dalam Jurnal "Rekam” Vol.06, Nomor 1, Fakultas Seni Media Rekam ISI Yogyakarta.

Sobur, Alex, 2009, Psikologi Umum, Pustaka Setia: Bandung.

Soemandoyo, Priyo, 1999, Wacana Gender dalam televisi : Studi Perempuan dalam Pemberitaan Televisi Swasta. Yogyakarta : LP3Y dan Ford Foundation.

Soedarso Sp., 2006, Trilogi Seni. Penciptaan, Eksistensi, dan Kegunaan Seni, Yogyakarta, BP ISI Yogyakarta.

Ruiz Jr., Conrado R., Sang N. Le, Jinze Yu \& Kok-Lim Low, 2014, Multi-style Paper Popup Designs from 3D Model, dalam Jurnal "Eurographics” Vol. 33, Nomor 2, John Wiley \& Sons Ltd.

\section{Referensi Online :}

Berton, Justin. 2006. "Seeking readers via 'book trailer' / Publisher tries out movie-style preview to market new title". http://www.sfgate.com/business/article/Seekingreaders-via-book-trailer-Publisher-2488096.php diakses pada 16 Juni 2015

Chmielewski, Dawn .2006. "YouTube video sets stage for novel" Los Angeles Times. http://articles.latimes.com/2006/nov/04/business/fi-vidbooks4 diakses pada 16 Juni 2015

Harper Collins Children Publishing. 2013. Book Trailer : "Fortunately, The Milk” by Neil Gaiman . http://www.youtube.com/watch?v=jrGr-WOjhU4 diakses pada 2 Februari 2012

Fox, Killian. 2006. "On a screen near you ...". http://www.theguardian.com/books/2006/jul/16/fiction.features7 diakses pada 6 Juni 2015

Jones, Brett. 2013, “The Illustrated History of Projection Mapping” http://projection-mapping.org/the-history-of-projection-mapping/ diakses pada 18 Agustus 2015

Kneschke, Tristan. 2012. "Don't Judge a Book by its Trailer". International Business

Times. http://www.ibtimes.com/dont-judge-book-its-trailer-413612 diakses pada 6 Juni 2015

Sambuchino, Chuck. 2013, "How to Make a Book Trailer: 6 Tips" http://www.writersdigest.com/editor-blogs/guide-to-literary-agents/how-to-make-abook-trailer-6-tips diakses pada 6 Juni 2015 
Nissa Fijriani

Book Trailer "Nawung, Puteri Malu dari Jawa" dengan Teknik Pop-Up Projection Mapping

(HALAMAN INI SENGAJA DIKOSONGKAN) 